\title{
Pengaruh Disiplin Kerja dan Komunikasi Terhadap Kinerja Pegawai di Dinas Pemberdayaan Masyarakat Desa (PMD) Kabupaten Musi Rawas Utara
}

\author{
Yulpa Rabeta*, Rudi Azhar, Yuli Efriyanti \\ Fakultas Ekonomi dan Bisnis, Manajemen, Universitas Bina Insan, Lubuklinggau, Indonesia \\ Email: 1," yulparabeta@yahoo.com, ${ }^{2}$ rudiazhar@gmail.com.com, ${ }^{3}$ yuliefriyanti2019@gmail.com \\ Email Penulis Korespondensi: yulparabeta@yahoo.com \\ Submitted: 11/11/2021; Accepted: 26/11/2021; Published: 30/11/2021
}

\begin{abstract}
Abstrak-Tujuan penelitian ini adalah untuk mengetahui Pengaruh Disiplin Kerja dan Komunikasi Terhadap Kinerja Pegawai di Dinas Pemberdayaan Masyarakat Desa (PMD) Kabupaten Musi Rawas Utara. Populasi dan sampel penelitian berjumlah 34 orang. Metode analisis data menggunakan analisis kuantitatif. Hasil penelitian menunjukkan Disiplin kerja berpengaruh terhadap Kinerja Pegawai Sedangkan uji t dijelaskan bahwa variabel disiplin (X1) terhadap kinerja menunjukan nilai thitung $=7,517$ Lebih besar dari nilai ttabel 1,692 dengan tingkat signifikan $=0,000<$ (a) 0,05 , hal ini menunjukan Ha diterima dan secara parsial variabel disiplin memiliki pengaruh yang signifikan terhadap kinerja. Komunikasi Terhadap Kinerja Pegawai Hasil uji t variabel komunikasi (X2) terhadap kinerja menunjukan nilai thitung $=7,756$ Lebih besar dari nilai ttabel 1,692 dengan tingkat signifikan $=0,000<$ (a) 0,05 , hal ini menunjukan Ha diterima dan secara parsial variabel komunikasi memiliki pengaruh yang signifikan terhadap kinerja. Berdasarkan rekapitulasi hasil uji regresi linier berganda, didapat bahwa nilai Fhitung yang diperoleh adalah 52,720 $>$ Ftabel $=3,28$ dan tingkat kemaknaan secara serentak sig F adalah 0,000. Hal ini menunjukkan bahwa secara bersama-sama (simultan) variabel bebas penelitian (disiplin dan komunikasi) memiliki pengaruh yang signifikan terhadap variabel terikat (kinerja).
\end{abstract}

Kata Kunci: Disiplin Kerja; Komunikasi; Kinerja

Abstract-The purpose of this study was to determine the effect of work discipline and communication on employee performance at the Village Community Empowerment Service (PMD) of North Musi Rawas Regency. The population and research sample amounted to 34 people. Methods of data analysis using quantitative analysis. The results showed that work discipline had an effect on employee performance. While the t-test explained that the discipline variable (X1) on performance showed the value of tcount $=7.517$, which was greater than the ttable value of 1.692 with a significant level $=0.000<$ (a) 0.05 , this indicates Ha is accepted. and partially discipline variable has a significant influence on performance. Communication on Employee Performance The results of the t-test of the communication variable (X2) on performance show the value of tcount $=7.756$ Greater than the value of ttable 1.692 with a significant level $=0.000<$ (a) 0.05 , this shows Ha is accepted and partially the communication variable has an influence significant to performance. Based on the recapitulation of multiple linear regression test results, it was found that the Fcount value obtained was $52.720>$ Ftable $=3.28$ and the simultaneous significance level of sig F was 0.000 . This shows that together (simultaneously) the independent variables of research (discipline and communication) have a significant effect on the dependent variable (performance).

Keywords: Work Discipline; Communication; Performance

\section{PENDAHULUAN}

Manajemen sumber daya manusia merupakan peran terpenting bagi manusia untuk menjalankan sebuah organisasi agar dapat terwujudnya tujuan bersama. Untuk itu perlu adanya peran aktif bagi pegawai yang didalamnya untuk menjalankan sebuah organisasi tersebut dan diatur berdasarkan manajemen sumber daya manusia yang di terapkan dalam organisasi tersebut. Keberhasilan suatu organisasi dapat dilihat dari kinerja pegawai atau aparaturnya. Kinerja karyawan yang merupakan hasil olah pikir dan tenaga dari seorang karyawan terhadap pekerjaan yang dilakukannya, dapat berwujud, dilihat, dihitung jumlahnya, akan tetapi banyak hal hasil olah pikiran dan tenaga tidak dapat dihitung dan dilihat. Dinas Pemberdayaan Masyarakat Desa (PMD) Kabupaten Musi Rawas Utara merupakan salah satu Instansi yang ada dalam tata pemerintahan, sedangkan fungsinya adalah melaksanakan penyusunan dan pelaksanaan kebijakan di bidang pemberdayaan masyarakat desa. Untuk melaksanakan tugas Dinas Pemberdayaan Masyarakat Desa (PMD) Kabupaten Musi Rawas Utara diperlukan suatu panduan yang mampu menunjukkan arah kegiatan prioritas dan kebijakan sesuai dengan Visi dan Misi yang ada.

Dalam pelaksanaan tugas pokok dan fungsi, Dinas Pemberdayaan Masyarakat Desa (PMD) Kabupaten Musi Rawas Utara masih terdapat masalah-masalah terutama yang berhubungan dengan kinerja para pegawainya. Hasil temuan dari pengamatan awal ditemukan fenomena-fenomena yang berhubungan dengan penurunan kinerja pegawai fenomena yang terjadi membuat kinerja para pegawai menjadi menurun seperti komunikasi kerja, disilin kerja dan kinerja pegawai. Permasalahan yang terjadi di Dinas PMD (Pemberdayaan Masyarakat Desa) dalam disiplin kerja hal yang diduga menjadi penyebab dari penurunan kinerja pegawai termasuk hal yang paling penting di organisasi, karena tanpa disiplin yang baik tidak mungkin tercipta proses kerja yang baik. Masalah disiplin kerja sampai saat ini masih belum terselesaikan adalah pegawai yang memakai seragam dan atribut tidak sesuai dengan hari yang ditetapkan, sebagian pegawai yang datang telat (4,05\% dan 5\% bulan Januari dan Februari 2021) dan pulang kerja cepat (3\% dan 2,7\% bulan Januari dan Februari 2021) sehingga tidak sesuai dengan jam yang telah di tentukan serta pegawai dalam mengerjakan tugas tidak siap bertanggung jawab atas kesalahan yang telah dilakukan. Komunikasi juga merupakan bagian yang paling penting dalam organisasi, sebab komunikasi yang tidak baik akan menimbulkan masalah yang akan merugikan perusahaan. Permasalahan dalam komunikasi kerja yang terjadi selama ini membuat kinerja pegawai menjadi menurun adalah hubungan antara pegawai 
kurang harmonias disebabkan oleh jalinan yang kurang baik dikarenakan kesibukan masing-masing, kurangnya pegawai dalam memberikan saran saat diskusi hal ini nampak dari kurangnya penguasan cara-cara penyampaian, ide, dan gagasan untuk masalah yang sedang diselesaikan, dan kurangnya komunikasi terhadap atasan di karenakan kurangnya pendekatan antara pegawai dan atasan.

Kinerja para pegawai menjadi menurun karena terdampak dari masalah masalah yang terjadi di lingkungannya seperti, kurang telitinya pegawai dalam menyelesaikan tugas dikarenakan pegawai sering mengerjalan tidak hati-hati, sambil bermain hp, mengerjakan dengan terburu-buru, membuat disipin pegawai menjadi rendah. Kinerja pegawai dalam menyelesaikan tugas masih rendah, di karenakan kurangnya kekompakan dan komunikasai sesama pegawai, dan kurangnya kerjasama tim dalam menyelesaikan tugas dikarenakan kurangnya kepercayaan sesama pegawai membuat pekerjaan menjadi lama diselesaikan.

\section{METODE PENELITIAN}

\subsection{Kerangka Dasar Penelitian}

Desain dalam penelitian ini yaitu, pertama Peneliti melakukan observasi di tempat penelitian, Peneliti mengidentifikasi masalah yang ada dari hasil observasi, Peneliti membuat kerangka pemikiran yang berisikan variabel bebas dan variabel terikat yang akan diteliti, Peneliti membuat hipotesis atau dugaan hasil sementara untuk menjawab rumusan masalah, Peneliti menetapkan tujuan yang ingin dicapai dari penelitian yang akan dilakukan. Selanjutnya, Peneliti membuat instrumen penelitian, dimana Peneliti membuat rancangan daftar pertanyaan atau penyataan yang akan digunakan dalam pengumpulan data. Kemudian dilanjutkan dengan pengumpulan data, setelah data diperoleh Peneliti melakukan pengolahan data menggunakan program SPSS 20, untuk memperoleh atau membuktikan hasil dari penelitian yang telah dilakukan. Setelah pengolahan data selesai dilakukan dan didapatkan hasil, maka dapat dilihat terbukti atau tidak jawaban sementara atau hipotesis yang telah ada.

\subsection{Uji Validitas dan Reliabilitas}

Dalam penelitian kuantitatif, untuk mendapatkan data yang valid, reliabel, dan objektif maka peneliti melakukan penyebaran instrument penelitian dengan test kevalidan instrumen kepada beberapa jumlah populasi, data yang diperoleh dan dianalisis dengan cara yang benar. Dalam penelitian kuantitatif untuk mendapatkan data yang valid dan reliabel, diuji validitas dan reliabilitiasnya dengan instrumen penelitian. (Sugiyono, 2016), menyatakan bahwa penelitian kuantitatif lebih menekankan pada aspek reliabilitas, sedangkan penelitian kuantitatif lebih pada aspek validitas.

\subsection{Uji Asumsi Klasik}

a. Uji Normalitas

Uji normalitas digunakan untuk mengetahui apakah variabel independen dan variabel dependen mempunyai distribusi normal atau tidak. Model regresi yang baik adalah data yang berdistribusi normal atau mendeteksi normal (Ghozali, 2016). Untuk menguji data berdistribusi normal atau tidak, yaitu dilihat melalui uji analisis statistic non-parametric Kolmogrov-Sminov (K-S) dan data yang dikatakan berdistribusi normal bila p-value Kolmogrov-Sminov Test >0,1.

b. Uji Linearitas

Uji linearitas bertujuan untuk mengetahui apakah antara variabel terikat (Y) dan variabel bebas (X) mempunyai hubungan linear (S. Siregar, 2017). Pada output, jika nilai signifikan Deviation from Linearity pada ANOVA Table lebih besar dari 0,05, maka hubungan independen dan dependen bersifat linear dan uji linearitasnya terpenuhi.

\subsection{Teknik Analisis Data}

Kegiatan analisis data meliputi pengolahan data dan penyajian data, melakukan perhitungan untuk mendeskripsikan data dan melakukan pengujian hipotesis dengan menggunakan uji statistik yang dibantu dengan menggunakan progam SPSS 20 (S. Siregar, 2017). Adapun uji statistik yang digunakan dalam penelitian ini yaitu uji regresi linear sederhana, uji koefisien korelasi, uji t (parsial), uji regresi linear berganda, uji koefisien determinasi dan uji F (simultan).

\section{HASIL DAN PEMBAHASAN}

\subsection{Hasil Penelitian}

\subsubsection{Hasil Uji Asumsi Klasik}

a. Uji Normalitas

Uji Normalitas dimasudkan untuk melihat tingkat kenormalan data. Pada uji Kolmogorov-Smirnov dapat ditentukan juga data berdistribusi normal atau tidak. Data dikatakan normal jika nilai Asymp. Sig. (2-tailed) menunjukkan signifikansi > 0,05. Hasil dapat dilihat pada tabel dibawah ini: 
Ekonomi, Keuangan, Investasi dan Syariah (EKUITAS)

Vol 3, No 2, November 2021, Hal 54-60

ISSN 2685-869X (media online)

DOI 10.47065/ekuitas.v3i2.1055

Tabel 1. Uji Normalitas

\begin{tabular}{llrrr}
\hline & & $\mathrm{X} 1$ & $\mathrm{X} 2$ & \multicolumn{1}{c}{$\mathrm{Y}$} \\
\hline $\mathrm{N}$ & & 34 & 34 & 34 \\
Normal Parameters & Mean & 49,06 & 62,62 & 87,74 \\
& Std. Deviation & 4,880 & 3,709 & 4,647 \\
& Absolute & 0,149 & 0,113 & 0,122 \\
Most Extreme Differences & Positive & 0,122 & 0,106 & 0,122 \\
& Negative & $-0,149$ & $-0,113$ & $-0,099$ \\
Kolmogorov-Smirnov Z & & 0,871 & 0,660 & 0,710 \\
Asymp. Sig. (2-tailed) & & 0,434 & 0,776 & 0,695 \\
\hline
\end{tabular}

Sumber: Data Primer SPSS Versi 20 Tahun 2021

Berdasarkan tabel 1 diatas nilai signifikansi untuk variabel Disiplin $\left(X_{1}\right)$ sebesar $0,434>0,05$, variabel Komunikasi $\left(\mathrm{X}_{2}\right)$ sebesar 0,776 > 0,05, dan variabel Kinerja 0,695 > 0,05. Maka dapat disimpulkan bahwa nilai residual berdistribusi normal.

b. Uji Linearitas

Uji linearitas bertujuan untuk mengetahui apakah dua variabel mempunyai hubungan yang linear atau tidak. Uji tersebut digunakan sebagai persyaratan dalam analisis kolerasi atau regresi linier.

Tabel 2. Disiplin $\left(\mathrm{X}_{1}\right)$ Terhadap Kinerja (Y)

\begin{tabular}{|c|c|c|c|c|c|c|c|}
\hline & & & $\begin{array}{l}\text { Sum of } \\
\text { Squares }\end{array}$ & $\mathrm{df}$ & Mean Square & $\mathrm{F}$ & Sig. \\
\hline \multirow{5}{*}{$\begin{array}{l}\mathrm{Y}^{*} \\
\mathrm{X} 1\end{array}$} & \multirow{3}{*}{ Between Groups } & (Combined) & 555,284 & 14 & 39,663 & 4,790 & 0,001 \\
\hline & & Linearity & 493,131 & 1 & 493,131 & 59,552 & 0,000 \\
\hline & & $\begin{array}{l}\text { Deviation from } \\
\text { Linearity }\end{array}$ & 62,153 & 13 & 4,781 & 0,577 & 0,843 \\
\hline & Sroups & & 157,333 & 19 & 8,281 & & \\
\hline & Total & & 712,618 & 33 & & & \\
\hline
\end{tabular}

Sumber : Data Primer SPSS Versi 20 Tahun 2021

Berdasarkan tabel 2 diatas nilai Linearity 0,000 $<0,05$ dan nilai Deviation from Linearity sebesar 0,843 >0,05 maka dapat disimpulkan bahwa terdapat hubungan antara variabel disiplin $\left(\mathrm{X}_{1}\right)$ terhadap kinerja $(\mathrm{Y})$.

Tabel 3. Komunikasi $\left(\mathrm{X}_{2}\right)$ Terhadap Kinerja $(\mathrm{Y})$

\begin{tabular}{|c|c|c|c|c|c|c|c|}
\hline & & & $\begin{array}{l}\text { Sum of } \\
\text { Squares }\end{array}$ & $\mathrm{df}$ & Mean Square & $\mathrm{F}$ & Sig. \\
\hline \multirow{5}{*}{$\begin{array}{l}\mathrm{Y}^{*} \\
\mathrm{X} 2\end{array}$} & \multirow{3}{*}{ Between Groups } & (Combined) & 578,284 & 11 & 52,571 & 8,610 & 0,000 \\
\hline & & Linearity & 465,156 & 1 & 465,156 & 76,179 & 0,000 \\
\hline & & $\begin{array}{l}\text { Deviation from } \\
\text { Linearity }\end{array}$ & 113,129 & 10 & 11,313 & 1,853 & 0,110 \\
\hline & Sroups & & 134,333 & 22 & 6,106 & & \\
\hline & Total & & 712,618 & 33 & & & \\
\hline
\end{tabular}

Sumber : Data Primer SPSS Versi 20 Tahun 2021

Berdasarkan tabel 3 diatas nilai Linearity 0,000 <0,05 dan nilai Deviation from Linearity sebesar 0,110 >0,05 maka dapat disimpulkan bahwa terdapat hubungan antara variabel komunikasi $\left(\mathrm{X}_{2}\right)$ terhadap kinerja $(\mathrm{Y})$.

\subsubsection{Teknik Analisis Data}

a. Analisis Regresi Linear Sederhana

Adapun hasil rekapitulasi analisis regresi sederhana selanjutnya dapat dilihat dari tabel berikut ini:

Tabel 4. Hasil Regresi Linier Sederhana Disiplin $\left(\mathrm{X}_{1}\right)$ Terhadap Kinerja $(\mathrm{Y})$

\begin{tabular}{|c|c|c|c|c|c|c|}
\hline \multirow[t]{2}{*}{$\overline{\text { Model }}$} & & \multicolumn{2}{|c|}{ Unstandardized Coefficients } & \multirow{2}{*}{$\begin{array}{c}\text { Standardized Coefficients } \\
\text { Beta }\end{array}$} & \multirow[t]{2}{*}{$\mathrm{t}$} & \multirow[t]{2}{*}{ Sig. } \\
\hline & & $\mathrm{B}$ & Std. Error & & & \\
\hline & (Constant) & 48,874 & 4,605 & & 10,613 & 0,000 \\
\hline 1 & $\mathrm{X} 1$ & 0,792 & 0,093 & 0,832 & 8,479 & 0,000 \\
\hline
\end{tabular}

Sumber : Data Primer SPSS Versi 20 Tahun 2021

Berdasarkan tabel 4 diatas dapat diketahui hasil perhitungan regresi linier sederhana, diperoleh nilai $b=0,792$ sedangkan nilai constant (a) $=48,847$ dari hasil output SPSS nilai tersebut dimasukan kedalam persamaan regresi linier sederhana sebagai berikut: 
$\mathrm{Y}=\mathrm{a}+\mathrm{bX} \mathrm{X}_{1}$

Kinerja $=48,874+0,792$ Disiplin

1. $\mathrm{a}=48,874$ adalah bilangan konstanta yang berarti apabila apabila variabel bebas yaitu disiplin $\mathrm{X}_{1}$ sama dengan nol, maka besarnya variabel kinerja Y adalah 48,874. Dengan kata lain jika variabel bebas (disiplin) nilainya dianggap nol berarti besarnya variabel terpengaruh (kinerja) adalah 48,874 .

2. $\mathrm{bX} 1=0,641$ adalah besarnya koefisien regresi variabel bebas disiplin $\left(\mathrm{X}_{1}\right)$, yang berarti setaip peningkatan (penambahan) variabel disiplin $\left(\mathrm{X}_{1}\right)$ akan meningkatkan variabel terikat kinerja $(\mathrm{Y})$ sebesar 0,641 . Jika variabel disiplin $\left(\mathrm{X}_{1}\right)$ ada kecenderungan meningkat maka kinerja pegawai akan meningkat.

Tabel 5. Hasil Regresi Linier Sederhana Komunikasi $\left(\mathrm{X}_{2}\right)$ Terhadap Kinerja (Y)

\begin{tabular}{|c|c|c|c|c|c|c|}
\hline \multirow[t]{2}{*}{ Model } & & \multicolumn{2}{|c|}{ Unstandardized Coefficients } & \multirow{2}{*}{$\begin{array}{l}\text { Standardized Coefficients } \\
\text { Beta }\end{array}$} & \multirow[t]{2}{*}{$\mathrm{t}$} & \multirow[t]{2}{*}{ Sig. } \\
\hline & & $\mathrm{B}$ & Std. Error & & & \\
\hline & (Constant) & 24,355 & 8,186 & & 2,975 & 0,006 \\
\hline 1 & $\mathrm{X} 2$ & 1,012 & 0,131 & 0,808 & 7,756 & 0,000 \\
\hline
\end{tabular}

Sumber : Data Primer SPSS Versi 20 Tahun 2021

Berdasarkan tabel 5 diatas dapat diketahui hasil perhitungan regresi linier sederhana, diperoleh nilai $\mathrm{b}=1,012$ sedangkan nilai constant $(\mathrm{a})=24,355$ dari hasil output SPSS nilai tersebut dimasukan kedalam persamaan regresi linier sederhana sebagai berikut:

$\mathrm{Y}=\mathrm{a}+\mathrm{bX} \mathrm{X}_{2}$

Kinerja $=24,355+0,1,012$ Komunikasi

1. $a=24,355$ adalah bilangan konstanta yang berarti apabila apabila variabel bebas yaitu komunkasi $X_{2}$ sama dengan nol, maka besarnya variabel kinerja Y adalah 24,355. Dengan kata lain jika variabel bebas (komunikasi) nilainya dianggap nol berarti besarnya variabel terpengaruh (kinerja) adalah 24,355.

2. $\mathrm{bX1}=1,012$ adalah besarnya koefisien regresi variabel bebas komunikasi $\left(\mathrm{X}_{2}\right)$, yang berarti setaip peningkatan (penambahan) variabel komunikasi $\left(\mathrm{X}_{2}\right)$ akan meningkatkan variabel terikat kinerja (Y) sebesar 1,012. Jika variabel komunikasi $\left(\mathrm{X}_{2}\right)$ ada kecenderungan meningkat maka kinerja pegawai akan meningkat.

b. Koefisien Korelasi

Penelitian korelasi adalah penelitian yang dilakukan untuk mengetahui ada atau tidak adanya hubungan antara dua variabel atau lebih. Jika ada hubungan seberapa besar hubungannya. Untuk menyatakan hubungan digunakan koefisien korelasi yang besarnya antara 0 sampai \pm 1 (-1 sampai +1$)$. Kofisien korelasi 0,000 sampai $+1,000$ disebut korelasi positif. Kofisien korelasi 0,000 sampai -1,000 disebut korelasi negatif.

Tabel 6. Hasil Uji Koefisien Korelasi Disiplin $\left(\mathrm{X}_{1}\right)$

\begin{tabular}{llrrr}
\hline Model & R & R Square & Adjusted R Square & Std. Error of the Estimate \\
\hline 1 & $0,832^{\mathrm{a}}$ & 0,692 & 0,682 & 2,619 \\
\hline
\end{tabular}

Sumber : Data Primer SPSS Versi 20 Tahun 2021

Berdasarkan tabel 3.6 di atas, dapat diketahui bahwa variabel disiplin (X) dan kinerja (Y) memiliki nilai koefisien sebesar 0,832 berada pada interval koefisien 0,000-1,000 yang berarti pengaruh antara variabel disiplin $\left(\mathrm{X}_{1}\right)$ dan variabel kinerja (Y) menunjukan pengaruh yang kuat dan nilai korelasi positif artinya korelasi atau hubungan pengaruh disiplin $\left(\mathrm{X}_{1}\right)$ terhadap Kinerja $(\mathrm{Y})$ searah.

Tabel 7. Hasil Uji Koefisien Korelasi Komunikasi $\left(\mathrm{X}_{2}\right)$

\begin{tabular}{llccr}
\hline Model & R & R Square & Adjusted R Square & Std. Error of the Estimate \\
\hline 1 & $0,808^{\mathrm{a}}$ & 0,653 & 0,642 & 2,781 \\
\hline \multicolumn{5}{c}{ Sumber : Data Primer SPSS Versi 20 Tahun 2021 }
\end{tabular}

Berdasarkan tabel 7 di atas, dapat diketahui bahwa variabel komunikasi $\left(\mathrm{X}_{2}\right)$ dan kinerja (Y) memiliki nilai koefisien sebesar 0,808 berada pada interval koefisien 0,000-1,000 yang berarti pengaruh antara variabel komunikasi $\left(\mathrm{X}_{2}\right)$ dan variabel kinerja (Y) menunjukan pengaruh yang sangat kuat dan nilai korelasi positif artinya korelasi atau hubungan pengaruh komunikasi $\left(\mathrm{X}_{2}\right)$ terhadap Kinerja $(\mathrm{Y})$ searah.

c. Uji t

Untuk melihat pengaruh pengaruh parsial dari masing-masing variabel bebas terhadap variabel terikat dapat dijelaskan dengan menggunakan uji t, hasil uji t secara rinci dapat disajikan pada tabel dibawah ini: 
Tabel 8. Hasil Uji t Disiplin $\left(\mathrm{X}_{1}\right)$

\begin{tabular}{|c|c|c|c|c|c|c|}
\hline \multirow{2}{*}{\multicolumn{2}{|c|}{ Model }} & \multicolumn{2}{|c|}{ Unstandardized Coefficients } & \multirow{2}{*}{$\begin{array}{l}\text { Standardized } \\
\text { Coefficients } \\
\text { Beta }\end{array}$} & \multirow[t]{2}{*}{$\mathrm{t}$} & \multirow[t]{2}{*}{ Sig. } \\
\hline & & B & Std. Error & & & \\
\hline 1 & (Constant) & 48,213 & 5,280 & & 9,131 & 0,000 \\
\hline 1 & $\mathrm{X} 1$ & 0,641 & 0,085 & 0,799 & 7,517 & 0,000 \\
\hline
\end{tabular}

Berdasarkan tabel 8 di atas dapat dijelaskan bahwa variabel disiplin $\left(\mathrm{X}_{1}\right)$ terhadap kinerja menunjukan nilai $t_{\text {hitung }}$ $=7,517$ Lebih besar dari nilai $t_{\text {tabel }} 1,692$ dengan tingkat signifikan $=0,000<$ (a) 0,05 , hal ini menunjukan Ha diterima dan secara parsial variabel disiplin memiliki pengaruh yang signifikan terhadap kinerja.

Tabel 9. Hasil Uji t Komunikasi

\begin{tabular}{|c|c|c|c|c|c|c|}
\hline \multirow{2}{*}{\multicolumn{2}{|c|}{ Model }} & \multicolumn{2}{|c|}{ Unstandardized Coefficients } & \multirow{2}{*}{$\begin{array}{c}\text { Standardized Coefficients } \\
\text { Beta }\end{array}$} & \multirow[t]{2}{*}{$\mathrm{t}$} & \multirow[t]{2}{*}{ Sig. } \\
\hline & & B & Std. Error & & & \\
\hline 1 & (Constant) & 24,355 & 8,186 & & 2,975 & 0,006 \\
\hline & $\mathrm{X} 2$ & 1,012 & 0,131 & 0,808 & 7,756 & 0,000 \\
\hline
\end{tabular}

Sumber: Data Primer SPSS Versi 20 Tahun 2021

Berdasarkan tabel 9 diatas dapat dijelaskan bahwa variabel komunikasi $\left(\mathrm{X}_{2}\right)$ terhadap kinerja menunjukan nilai $t_{\text {hitung }}=7,756$ Lebih besar dari nilai $t_{\text {tabel }} 1,692$ dengan tingkat signifikan $=0,000<$ (a) 0,05 , hal ini menunjukan Ha diterima dan secara parsial variabel komunikasi memiliki pengaruh yang signifikan terhadap kinerja.

d. Regresi Lienar Berganda

Regresi liner berganda bertujuan untuk mengetahuni pengaru antara disiplin dan komunkasi terhadap kinerja pegawai, bentuk persamaanya adalah sebagi berikut:

Tabel 10. Hasil Uji Regresi Liner Berganda

\begin{tabular}{rlrrrrr}
\hline Model & \multicolumn{3}{c}{ Unstandardized Coefficients } & \multicolumn{2}{c}{$\begin{array}{c}\text { Standardized Coefficients } \\
\text { Beta }\end{array}$} & \multicolumn{2}{c}{ Sig. } \\
& \multicolumn{1}{c}{ B } & Std. Error & & & 4,392 & 0,000 \\
1 & (Constant) & 27,608 & 6,285 & 0,526 & 4,888 & 0,000 \\
& X1 & 0,501 & 0,103 & 0,453 & 4,206 & 0,000 \\
\hline
\end{tabular}

Sumber : Data Primer SPSS Versi 20 Tahun 2021

Dari hasil rekapitulasi hasi regresi linear berganda di atas adapun persamaan regresi untuk mengestimasi variabel terikat dengan menggunakan seluruh variabel bebas adalah sebagai berikut :

$\mathrm{Y}=27,608+0,501 \mathrm{X}_{1}+0,567 \mathrm{X}_{2}$

Hasil uji Regresi Linear berganda menunjukan bahwa ini:

1. Nilai (constant) menunjukan nilai sebesar 27,608artinya jika nilai variabel independent (disiplin dan komunikasi) nol maka nilai varibel dependen (kinerja) sebesar 27,608 dalam hal ini bila variabel independen naik atau bepengaruh dalam satu satuan, maka variabel bebas akan naik atau terpenuhi.

2. Nilai koefisien regresi variabel disiplin $\left(\mathrm{X}_{1}\right)$ terhadap variabel kinerja $(\mathrm{Y})$ sebesar $\mathrm{b}_{1}=0,501$ artinya jika disiplin $\left(\mathrm{X}_{1}\right)$ mengalami kenaikan satu satuan, maka akan mengalami peningkatan kinerja sebesar 0,501 .

3. Nilai koefisien regresi variabel komunikasi $\left(\mathrm{X}_{2}\right)$ terhadap kinerja $(\mathrm{Y})$ sebesar $\mathrm{b}_{2}=0,567$ artinya jika komunikasi $\left(\mathrm{X}_{2}\right)$ mengalami kenaikan satu satuan, maka akan mengalami peningkatan kinerja sebesar 0,567 .

e. Koefisien Determinasi

Hasil uji koefisien determinasi $\left(\mathrm{R}^{2}\right)$ dapat dilihatdi Tabel 3.11 sebagai berikut:

Tabel 11. Hasil uji F

\begin{tabular}{llrrr}
\hline Model & $\mathrm{R}$ & $\mathrm{R}$ Square & Adjusted R Square & Std. Error of the Estimate \\
\hline 1 & $0,897^{\mathrm{a}}$ & 0,804 & 0,791 & 2,123 \\
\hline
\end{tabular}

Sumber : Data Primer SPSS Versi 20 Tahun 2021

Berdasarkan dari tabel diatas, dapat di simpulkan berdasarkan nilai determinasi $\mathrm{R}=0,897$ memperlihatkan adanya pengaruh yang kuat antara disiplin dan komunikasi terhadap kinerja. Sedangkan koefisien determinasi R2 (R Square) $0,897(89,7 \%)$ artinya disiplin $\left(\mathrm{X}_{1}\right)$ dan komunikasi $\left(\mathrm{X}_{2}\right)$ secara bersama-sama memberikan kontribusi terhadap kinerja (Y) dan setelah di sesuaikan nilainya $100-89,7 \%=10,3 \%$ dipengaruhi variabel lain yang tidak dimasukan dalam penelitian ini seperti variabel lingkungan kerja, budaya organisasi, kompetensi, motivasi dan sebagainya. 


\section{f. $U j i \mathrm{~F}$}

Hasil dari uji F (simultan) variabel disiplin kerja dan komunikasi terhadap kinerja pegawai di Dinas Pemberdayaan Masyarakat Desa (PMD) Kabupaten Musi Rawas Utara dapat dilihat pada tabel 12 di bawah ini:

Tabel 12. Hasil uji F

\begin{tabular}{llrrrrr}
\hline Model & & Sum of Squares & df & Mean Square & F & Sig. \\
\hline \multirow{2}{*}{1} & Regression & 572,867 & 2 & 286,434 & 63,538 & $0,000^{\mathrm{b}}$ \\
& Residual & 139,750 & 31 & 4,508 & & \\
\cline { 2 - 7 } & Total & 712,618 & 33 & & & \\
\hline
\end{tabular}

Sumber : Data Primer SPSS Versi 20 Tahun 2021

Uji serentak/simultan (uji F) dilakukan untuk melihat pengaruh dari variabel bebas terhadap variabel terikat secara bersama. Berdasarkan rekapitulasi hasil uji regresi linier berganda, didapat bahwa nilai $F_{\text {hitung }}$ yang diperoleh adalah $63,538>\mathrm{F}_{\text {tabel }}=3,28$ dan tingkat kemaknaan secara serentak sig $\mathrm{F}$ adalah 0,000. Hal ini menunjukkan bahwa secara bersama-sama (simultan) variabel bebas penelitian (disiplin dan komunikasi) memiliki pengaruh yang signifikan terhadap variabel terikat (kinerja). Hasil uji serentak/simultan (uji F) ini juga membuktikan bahwa hipotesis ketiga penelitian ini yang berbunyi disiplin dan komunikasi berpengaruh terhadap kinerja pegawai Dinas Pemberdayaan Masyarakat Desa (PMD) Muratara.

\subsection{Pembahasan}

a. Pengaruh Disiplin Terhadap Kinerja

Hasil uji normaltas nilai signifikansi untuk variabel Disiplin $\left(\mathrm{X}_{1}\right)$ sebesar $0,735>0,05$, maka dapat disimpulkan bahwa nilai residual berdistrinusi normal. Berdasarka uji linieritas didapatkan nilai Linearity $0,000<0,05$ dan nilai Deviation from Linearity sebesar 0,920 > 0,05 maka dapat disimpulkan bahwa terdapat hubungan antara variabel disiplin $\left(\mathrm{X}_{1}\right)$ terhadap kinerja (Y). Selanjutnya hasil perhitungan regresi linier sederhana, diperoleh nilai $b=0,641$ sedangkan nilai constant (a) $=48,213$ dari hasil output SPSS nilai tersebut dimasukan kedalam persamaan regresi linier sederhana sebagai berikut: $\mathrm{Y}=\mathrm{a}+\mathrm{bX}$. Kinerja $=48,213+0,641$ Disiplin $\mathrm{a}=48,213$ adalah bilangan konstanta yang berarti apabila apabila variabel bebas yaitu disiplin $X_{1}$ sama dengan nol, maka besarnya variabel kinerja $Y$ adalah 48,213. Dengan kata lain jika variabel bebas (disiplin) nilainya dianggap nol berarti besarnya variabel terpengaruh (kinerja) adalah 48,213. $\mathrm{bX} 1=0,641$ adalah besarnya koefisien regresi variabel bebas disiplin $\left(\mathrm{X}_{1}\right)$, yang berarti setaip peningkatan (penambahan) variabel disiplin $\left(\mathrm{X}_{1}\right)$ akan meningkatkan variabel terikat kinerja (Y) sebesar 0,641. Jika variabel disiplin $\left(\mathrm{X}_{1}\right)$ ada kecenderungan meningkat maka kinerja pegawai akan meningkat. Kemudian hasil dari koefisien korelasi variabel disiplin $(\mathrm{X})$ dan kinerja $(\mathrm{Y})$ memiliki nilai koefisien sebesar 0,799 berada pada interval koefisien 0,000-1,000 yang berarti pengaruh antara variabel disiplin $\left(\mathrm{X}_{1}\right)$ dan variabel kinerja $(\mathrm{Y})$ menunjukan pengaruh yang kuat dan nilai korelasi positif artinya korelasi atau hubungan pengaruh disiplin $\left(\mathrm{X}_{1}\right)$ terhadap Kinerja (Y) searah. Sedangkan uji $t$ dijelaskan bahwa variabel disiplin $\left(\mathrm{X}_{1}\right)$ terhadap kinerja menunjukan nilai $\mathrm{t}_{\text {hitung }}=7,517$ Lebih besar dari nilai tabel 2,036 dengan tingkat signifikan $=0,000<$ (a) 0,05 , hal ini menunjukan Ha diterima dan secara parsial variabel disiplin memiliki pengaruh yang signifikan terhadap kinerja.

b. Pengaruh Komunikasi Terhadap Kinerja

Hasil uji normalitas nilai variabel Komunikasi $\left(\mathrm{X}_{2}\right)$ sebesar 0,776 >0,05. Maka dapat disimpulkan bahwa nilai residual berdistrinusi normal. Hasil uji Linieritas didapatkan nilai Linearity $0,000<0,05$ dan nilai Deviation from Linearity sebesar 0,110>0,05 maka dapat disimpulkan bahwa terdapat hubungan antara variabel komunikasi $\left(\mathrm{X}_{2}\right)$ terhadap kinerja (Y). Selanjutnya hasil regresi linier sederhana, diperoleh nilai $b=1,012$ sedangkan nilai constant $(a)=24,355$ dari hasil output SPSS nilai tersebut dimasukan kedalam persamaan regresi linier sederhana sebagai berikut: $\mathrm{Y}=$ $\mathrm{a}+\mathrm{bX}$. Kinerja $=24,355+1,012$ Komunikasi $\mathrm{a}=24,355$ adalah bilangan konstanta yang berarti apabila apabila variabel bebas yaitu komunkasi $X_{2}$ sama dengan nol, maka besarnya variabel kinerja $Y$ adalah 24,355. Dengan kata lain jika variabel bebas (komunikasi) nilainya dianggap nol berarti besarnya variabel terpengaruh (kinerja) adalah 24,355 . $\mathrm{bX} 1=1,012$ adalah besarnya koefisien regresi variabel bebas komunikasi $\left(\mathrm{X}_{2}\right)$, yang berarti setaip peningkatan (penambahan) variabel komunikasi $\left(\mathrm{X}_{2}\right)$ akan meningkatkan variabel terikat kinerja $(\mathrm{Y})$ sebesar 1,012. Jika variabel komunikasi $\left(\mathrm{X}_{2}\right)$ ada kecenderungan meningkat maka kinerja pegawai akan meningkat. Kemudian hasil dari uji koefisin korelasi variabel komunikasi $\left(\mathrm{X}_{2}\right)$ dan kinerja $(\mathrm{Y})$ memiliki nilai koefisien sebesar 0,808 berada pada interval koefisien 0,000-1,000 yang berarti pengaruh antara variabel komunikasi $\left(\mathrm{X}_{2}\right)$ dan variabel kinerja $(\mathrm{Y})$ menunjukan pengaruh yang sangat kuat dan nilai korelasi positif artinya korelasi atau hubungan pengaruh komunikasi $\left(\mathrm{X}_{2}\right)$ terhadap Kinerja $(\mathrm{Y})$ searah. Hasil uji t variabel komunikasi $\left(\mathrm{X}_{2}\right)$ terhadap kinerja menunjukan nilai $\mathrm{t}_{\text {hitung }}=7,756$ Lebih besar dari nilai $t_{\text {tabel }} 2,036$ dengan tingkat signifikan $=0,000<$ (a) 0,05 , hal ini menunjukan Ha diterima dan secara parsial variabel komunikasi memiliki pengaruh yang signifikan terhadap kinerja.

c. Pengaruh Disiplin dan Komunikasi Terhadap Kinerja

Dari hasil rekapitulasi hasi regresi linear berganda di atas adapun persamaan regresi untuk mengestimasi variabel terikat dengan menggunakan seluruh variabel bebas adalah sebagai berikut : $\mathrm{Y}=27,608+0,501 \mathrm{X}_{1}+0,567 \mathrm{X}_{2 . .}$ Hasil uji Regresi Linear berganda menunjukan bahwa ini:Nilai (constant) menunjukan nilai sebesar 27,608artinya jika nilai variabel independent (disiplin dan komunikasi ) nol maka nilai varibel dependen (kinerja) sebesar 27,608 dalam hal ini bila variabel independen naik atau bepengaruh dalam satu satuan, maka variabel bebas akan naik atau 
terpenuhi.Nilai koefisien regresi variabel disiplin $\left(\mathrm{X}_{1}\right)$ terhadap variabel kinerja $(\mathrm{Y})$ sebesar $\mathrm{b}_{1}=0,501$ artinya jika disiplin $\left(\mathrm{X}_{1}\right)$ mengalami kenaikan satu satuan, maka akan mengalami peningkatan kinerja sebesar 0,501.Nilai koefisien regresi variabel komunikasi $\left(\mathrm{X}_{2}\right)$ terhadap kinerja $(\mathrm{Y})$ sebesar $\mathrm{b}_{2}=0,567$ artinya jika komunikasi $\left(\mathrm{X}_{2}\right)$ mengalami kenaikan satu satuan, maka akan mengalami peningkatan kinerja sebesar 0,567 . Selanjutnya hasil uji koefisien determinasi dapat di simpulkan berdasarkan nilai determinasi $R=0,897$ memperlihatkan adanya pengaruh yang kuat antara disiplin dan komunikasi terhadap kinerja. Sedangkan koefisien determinasi R2 (R Square) 0,897 $(89,7 \%)$ artinya disiplin $\left(\mathrm{X}_{1}\right)$ dan komunikasi $\left(\mathrm{X}_{2}\right)$ secara bersama-sama memberikan kontribusi terhadap kinerja $(\mathrm{Y})$ dan setelah di sesuaikan nilainya $100-89,7 \%=10,3 \%$ dipengaruhi variabel lain yang tidak dimasukan dalam penelitian ini seperti variabel lingkungan kerja, budaya organisasi, kompetensi, motivasi dan sebagainya. Kemudian uji serentak/simultan (uji F) didapat bahwa nilai $F_{\text {hitung }}$ yang diperoleh adalah 63,538 $>F_{\text {tabel }}=3,28$ dan tingkat kemaknaan secara serentak sig F adalah 0,000. Hal ini menunjukkan bahwa secara bersama-sama (simultan) variabel bebas penelitian (disiplin dan komunikasi) memiliki pengaruh yang signifikan terhadap variabel terikat (kinerja).

\section{KESIMPULAN}

Berdasarkan hasil penelitian yang sudah di uraikan di atas maka dapat disimpulkan terdapatnya pengaruh positif dan signifikan antara disiplin kerja terhadap kinerja pegawai, hal ini menunjukan Ha diterima dan secara parsial variabel disiplin memiliki pengaruh yang signifikan terhadap kinerja pegawai. Adanya pengaruh positif dan signifikan antara komunikasi terhadap kinerja pegawai, hal ini menunjukan Ha diterima dan secara parsial variabel komunikasi memiliki pengaruh yang signifikan terhadap kinerja pegawai. Adanya pengaruh positif dan signifikan antara disiplin kerja dan komunikasi terhadap kinerja pegawai, hal ini menunjukkan bahwa secara bersama-sama variabel disiplin dan komunikasi memiliki pengaruh yang signifikan terhadap variabel kinerja.

\section{UCAPAN TERIMAKASIH}

Terima kasih disampaikan kepada pihak-pihak yang telah mendukung terlaksananya penelitian ini.

\section{REFERENCES}

Ghozali, I. (2016). Aplikasi Analisis Multivariate dengan Program IBM SPSS 23. Semarang: Badan Penerbit Universitas Diponegoro. Hartono. (2019). Metodologi Penelitian di Lengkapi Analisis Regresi dan Path Analysis Dengan IBM SPSS Statistik Version 25. Bandung: Zanafa Publising.

Hasibuan, M. (2020). Manajemen Sumber Dasya Manusia. Jakarta: PT. Bumi Aksara.

Jannah, M., Barlian, N. A., \& Sulistyan, R. B. (2020). Work Discipline and Communication Agaist Job Performance, Vol 3.

Kasmir. (2019). Manajemen Sumber Daya Manusia (Terori dan Praktik). Depok: PT. Rajagrafindo Persada.

Mangkunegara, (Anwar Prabu. (2020). Manajemen Sumber Daya Manusia. Bandung: PT. Remaja Rosdakarya.

Sugiyono. (2019). Metode Penelitihan Kuantitatif, Kualitatif, dan R\&D. Bandung: Alfabeta, .

Sujarweni. (2015). Metodologi Penelitian - Bisnis \& Ekonomi. Yogyakarta: Pustakabaruperss.

Suranto. (2020). Komunikasi Organisasi. Bandung: PT. Remaja Rosdakarya.

Syofian, S. (2017). Statistik Parametrik untuk Penelitian Kuantitatif Dilengkapi dengan Perhitungan Manual dan Aplikasi SPSS Versi 17. Jakarta : Bumi Aksara

Wibowo. (2016). Manajemen Kinerja. Jakarta: PT. Rajagrafindo Persada.

Siregar, S. (2017). Statistik Parametrik untuk Penelitian Kuantitatif Dilengkapi dengan Perhitungan Manual dan Aplikasi SPSS Versi 17. Jakarta: Bumi Aksara.

Sugiyono. (2016). Metode Penelitian Pendidikan Pendekatan, Kuantitatif, Kualitatif, dan R\&D. Bandung: Alfabeta. 